\title{
ANÁLISE DA COR E DA ATIVIDADE ANTIMICROBIANA DE MICROCÁPSULAS CONTENDO LACTOFERRINA BOVINA
}

\author{
LUCIANA HELENA MAIA PORTE* \\ MARIA HELENA MIGUEZ ROCHA LEÃO**

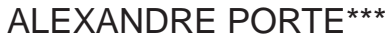

\begin{abstract}
Lactoferrina bovina (bLF), proveniente do soro de leite, foi microencapsulada pela técnica de spray drying. Microcápsulas contendo $20 \%$ de bLF foram produzidas, utilizando-se como material de parede dextrina: amido octenilsuccinato (OSA) em diferentes proporções: 100:00, 75:25, 50:50, 25:75 e 0:100 \%. Foram avaliadas a cor e a estabilidade de cor das microcápsulas sob armazenamento em ambientes com diferentes umidades relativas e a atividade antimicrobiana da lactoferrina liberada das microcápsulas. As microcápsulas apresentaram cor clara e tenderam a escurecer sob armazenamento em ambiente com alta umidade relativa. Verificou-se atividade inibitória das microcápsulas de bLF produzidas para diferentes bactérias Gram positivas (Bacillus subtilis CCT 2576, Staphylococcus aureus CCT 2740, Micrococcus luteus CCT 2692, Enterococcus faecium CCT 5079, Streptococcus faecium ATCC 10541, Rhodococcus equi CCT 0541), Gram negativas (Pseudomonas aeruginosa ATCC 13388, Salmonella choleraesius CCT 4296, Escherichia coli CCT 0547) e levedura (Candida albicans ATCC 10231). A concentração inibitória mínima (MIC) das microcápsulas variou de acordo com o microorganismo testado (MIC entre 2,5-100 mg. $\mathrm{mL}^{-1}$ ). Com exceção de B. subtilis (MIC entre $50-100 \mathrm{mg} \cdot \mathrm{mL}^{-1}$ para as microcápsulas), a concentração de bLF contida nas microcápsulas necessária para inibir o crescimento dos micro-organismos foi menor do que a bLF nativa. Esses resultados sugerem efeito de potencialização da atividade antimicrobiana da bLF após o processamento por spray drying.
\end{abstract}

PALAVRAS-CHAVE: MICROENCAPSULAÇÃO; SPRAY DRYING; LACTOFERRINA.

* Doutora em Ciências, Professor Adjunto, Instituto Multidisciplinar, Universidade Federal Rural do Rio de Janeiro, Nova Iguaçu, RJ (e-mail: Ihmaia@ufrrj.br).

** Doutora em Bioquímica, Professor Associado, Departamento de Engenharia Bioquímica, Escola de Química, Universidade Federal do Rio de Janeiro, Rio de Janeiro, RJ (e-mail: mhrl@eq.ufrj.br).

*** Doutor em Ciências, Professor Adjunto, Departamento de Tecnologia de Alimentos, Escola de Nutrição, Centro de Ciências Biológicas e da Saúde, Universidade Federal do Estado do Rio de Janeiro, Rio de Janeiro, RJ (e-mail: alexandre.porte@unirio.br). 


\section{INTRODUÇÃO}

Restrições ao emprego de conservantes em alimentos, bem como a demanda crescente por produtos "all-natural", têm voltado à atenção da indústria para substâncias com propriedades antimicrobianas naturalmente presentes em alimentos.

A lactoferrina bovina (bLF), glicoproteína ligante de ferro, é encontrada em fluidos exócrinos de mamíferos, como o leite (FARNAUD e EVANS, 2003). A lactoferrina, agente antimicrobiano natural, apresenta ampla ação contra bactérias Gram positivas e Gram negativas (AL-NABULSI e HOLLEY, 2007) e potencial para utilização pela indústria de alimentos (MURDOCK e MATTHEWS, 2002). Além disto, a bLF tem ação antioxidante, antiviral, antinflamatória, moduladora do sistema imunológico e pode melhorar o crescimento de bactérias probióticas como Bifidobacterium $s p$. (AGUILA e BROCK, 2001).

A atividade antimicrobiana da lactoferrina foi atribuída, por muitos anos, à sua habilidade de sequestrar o ferro do meio privando os patógenos desse nutriente essencial (FARNAUD e EVANS, 2003). Entretanto, estudos verificaram que a lactoferrina apresenta regiões catiônicas em sua superfície que facilitam sua interação com o lipídeo $A$, que é um componente dos lipopolissacarídeos da membrana de bactérias Gram negativas. Essa interação ocasiona dano à parede celular bacteriana, modificando sua permeabilidade e levando ao colapso da bactéria (APPELMELK et al., 1994).

A utilização da bLF como ingrediente em sistemas alimentares pode ser limitada pela sua cor avermelhada. Ademais, segundo Shimazaki (2000), a sua funcionalidade como agente antimicrobiano torna-se reduzida na presença de cátions divalentes, como cálcio e magnésio, encontrados em vários alimentos.

A microencapsulação, processo em que ingredientes sensíveis são protegidos de condições adversas do ambiente pelo agente encapsulante (HOGAN et al., 2001), representa alternativa para a utilização da lactoferrina nos mais diversos sistemas alimentares. As microcápsulas produzidas por esse processo apresentam características físicas e químicas resultantes da combinação entre o material de parede e o núcleo utilizado. Dessa maneira, as microcápsulas podem apresentar estado físico, forma, textura e cor diferentes da sua matéria-prima de origem.

Durante o processamento térmico, o alimento pode ser exposto a temperaturas que exercem efeito adverso na sua qualidade, tornando-o suscetível à descoloração (AVILA e SILVA, 1999). Segundo Wong e Stanton (1992), a mudança da cor do produto ocorre devido a componentes reativos ativados no alimento durante o processo de secagem. A alteração da cor resulta de várias reações como o escurecimento não enzimático, a destruição de pigmentos e a oxidação de cromóforos, como o ferro.

A avaliação da cor pode ser utilizada como meio indireto para estimar as alterações ocorridas nas microcápsulas, como a desintegração da sua microestrutura por absorção de água e o escurecimento das microcápsulas devido à oxidação do núcleo por ação do oxigênio, entre outras.

A análise visual de objetos pode ser definida como o resultado da interação entre três elementos distintos: fonte de luz, o objeto iluminado e o mecanismo receptor da luz (observador). Esses fatores são, similarmente, essenciais para a medida e especificação instrumental da cor (HUTCHINGS, 1994). A cor pode ser caracterizada mediante espectrofotômetro em determinado comprimento de onda ou por colorímetro triestímulo, sendo o último adequado e bastante utilizado para avaliação da descoloração e para fornecer informações para o controle de qualidade de produtos alimentícios (MASKAN, 2001).

A análise instrumental da cor vem sendo utilizada para avaliação de microcápsulas. Rocha, Fávaro-Trindade e Grosso (2011) utilizaram a análise instrumental da cor para avaliação de sistemas alimentares adicionados de licopeno microencapsulado, enquanto Pitalua et al. (2010) avaliaram a cor e a estabilidade do suco de beterraba microencapsulado.

Considerando que a aparência do alimento concorre grandemente para a sua aceitabilidade 
e que o emprego de lactoferrina bovina como agente antimicrobiano em sistemas alimentares pode ser limitado pela sua cor, o presente trabalho teve por objetivo microencapsular a bLF e avaliar a cor das microcápsulas produzidas e suas alterações quando armazenadas em ambientes com diferentes umidades relativas. Pretendeu-se também verificar a preservação da atividade antimicrobiana da bLF após a microencapsulação.

\section{MATERIAL E MÉTODOS}

\subsection{MATÉRIAS-PRIMAS UTILIZADAS}

Para obtenção das microcápsulas utilizou-se como núcleo a bLF purificada do soro de leite, adquirida da Biopole S.A./NV. Os materiais de parede, dextrina (Nadex $772^{\circledR}$ ) e amido octenilsuccinato ou amido OSA (Capsul ${ }^{\circledR}$ ) foram doados para o presente estudo pela National Starch and Chemical Company.

\subsection{PREPARO DAS SUSPENSÕES}

Foram preparados $400 \mathrm{~mL}$ de suspensão contendo $120 \mathrm{~g}$ de sólidos (30 \% p/v), sendo $24 \mathrm{~g}$ do teor de sólidos correspondente ao núcleo e $96 \mathrm{~g}$ ao material de parede.

Os materiais de parede (somente dextrina, somente amido OSA ou combinações de ambos em diferentes proporções) foram dispersos em $300 \mathrm{~mL}$ de água deionizada a $80{ }^{\circ} \mathrm{C}$, sendo o restante de água $(100 \mathrm{~mL})$ utilizados para solubilizar a bLF. Após o resfriamento da suspensão contendo o material de parede, a solução de bLF foi incorporada e homogeneizada lentamente.

Foram elaboradas cinco formulações, variando-se o tipo e a concentração do material de parede. A Tabela 1 apresenta as quantidades de bLF e de materiais de parede utilizados para obtenção das suspensões, que após secagem geraram as microcápsulas correspondentes.

TABELA 1 - FORMULAÇÕES UTILIZADAS PARA O PREPARO DAS SUSPENSÕES

\begin{tabular}{lcccccc}
\hline & \multicolumn{3}{c}{ Material de parede } & \multicolumn{3}{c}{ Núcleo } \\
\cline { 2 - 7 } Formulação & \multicolumn{2}{c}{ Dextrina } & \multicolumn{2}{c}{ Amido OSA } & \multicolumn{3}{c}{ bLF } \\
& $g$ & $\%^{*}$ & $\mathrm{~g}$ & $\%^{*}$ & $\mathrm{~g}$ & $\%^{*}$ \\
\hline CAP 0 & 96 & 80 & - & - & 24 & 20 \\
CAP 25 & 72 & 60 & 24 & 20 & 24 & 20 \\
CAP 50 & 48 & 40 & 48 & 40 & 24 & 20 \\
CAP 75 & 24 & 20 & 72 & 60 & 24 & 20 \\
CAP 100 & - & - & 96 & 80 & 24 & 20 \\
\hline
\end{tabular}

* percentual em relação ao teor de sólidos da suspensão.

\subsection{PRODUÇÃO DAS MICROCÁPSULAS}

As microcápsulas foram produzidas a partir da secagem das suspensões, descritas na Tabela 1, em spray dryer Mini Büchi 190 (Büchi Laboratoriums Technik AG) com as seguintes condições de operação: bico atomizador de $0,3 \mathrm{~mm}$, vazão de alimentação de $18 \mathrm{~mL} \cdot \mathrm{min}^{-1}$, temperatura de entrada e saída igual a $180^{\circ} \mathrm{C}$ e $90^{\circ} \mathrm{C}$, respectivamente (MAIA PORTE, ROCHA LEÃO e PORTE, 2011). 


\subsection{ANÁLISE INSTRUMENTAL DE COR DAS MICROCÁPSULAS}

Realizou-se a avaliação instrumental da cor em espectrofotômetro Minolta CM-3720d, usando o modelo de calibração de refletância especular incluída, geometria ótica $\mathrm{D} / \mathrm{O}$, iluminante $D_{65}$ e ângulo visual de $10^{\circ}$. As coordenadas CIELab $\left(L^{*}=\right.$ luminosidade; $a^{*}=$ vermelho/verde e $\mathrm{b}^{*}=$ amarelo/azul) foram lidas diretamente do aparelho.

Efetuou-se a avaliação instrumental da cor do amido OSA, da dextrina, da bLF e das microcápsulas produzidas, consideradas como Controle para verificar alterações da cor das microcápsulas após seu acondicionamento em dessecadores com diferentes umidades relativas (produzidas por soluções salinas saturadas). As soluções salinas saturadas apresentadas na Tabela 2 foram preparadas para produzir diferentes umidades relativas (11,3\% a $97 \%$ ), sendo cada uma delas colocada em dessecador ( $\phi 200 \mathrm{~mm}$ ). Pesou-se 0,5 g das microcápsulas (base seca) em placas de Petri, as quais foram acondicionadas nos dessecadores e esses colocados em câmara a $30^{\circ} \mathrm{C}$ durante 22 dias. Efetuou-se a avaliação da cor das microcápsulas, em duplicata, ao final desse período.

TABELA 2 - UMIDADE RELATIVA (\%) DAS SOLUÇÕES SALINAS SATURADAS A $30^{\circ} \mathrm{C}$

Soluções Salinas Saturadas

$\begin{array}{rr}\mathrm{LiCl} & 11,3 \\ \mathrm{MgCl}_{2} & 32,9 \\ \mathrm{~K}_{2} \mathrm{CO}_{3} & 44,7 \\ \mathrm{NaCl} & 76,9 \\ \mathrm{~K}_{2} \mathrm{SO}_{4} & 97,0\end{array}$

Umidade Relativa

(\%)

11,3

32,9

44,7

97,0

Fonte: GREENSPAN (1977); LABUZA (1983).

\subsection{DETERMINAÇÃO DA ATIVIDADE ANTIMICROBIANA DAS MICROCÁPSULAS}

As análises de atividade antimicrobiana das microcápsulas foram realizadas de acordo com a metodologia de Ellof (1998).

Nos testes de atividade antimicrobiana das amostras estudadas foram utilizados os seguintes micro-organismos: Bacillus subtilis CCT 2576, Escherichia coli CCT 0547, Staphylococcus aureus CCT 2740, Micrococcus luteus CCT 2692, Rhodococcus equi CCT 0541, Salmonella choleraesius CCT 4296, Pseudomonas aeruginosa ATCC 13388, Enterococcus faecium CCT 5079, Streptococcus faecium ATCC 10541, Candida albicans ATCC 10231.

As bactérias foram preservadas em meio Nutriente Agar inclinado, contendo (g. $\mathrm{L}^{-1}$ ): extrato de carne, 3; peptona de carne, 5; ágar-ágar, 15; pH 7. Preservou-se a levedura Candida albicans em Agar Saboraud Dextrose, contendo (g.L-1): peptona, 10; glicose, 40; ágar-ágar, 15.

Efetuou-se a manutenção das culturas por repicagem periódica no meio, seguida de incubação a $36{ }^{\circ} \mathrm{C}$ no caso das bactérias e a $28{ }^{\circ} \mathrm{C}$ para Candida albicans até crescimento. A estocagem ocorreu sob refrigeração a $5{ }^{\circ} \mathrm{C}$, e réplicas das culturas foram preservadas em óleo mineral e em criotubos.

Em microplaca esterilizada de 96 orifícios ou poços (12 colunas [1-12] e 8 linhas [AH]) foram depositados $100 \mu \mathrm{L}$ de caldo Mueller-Hinton, com exceção da coluna 12, utilizada para os controles do meio e de crescimento do micro-organismo. Dessa maneira, cada coluna correspondia a uma amostra testada (CAP 0, CAP 25, CAP 50, CAP 75, CAP 100 e bLF) e do padrão utilizado (cloranfenicol e nistatina). Por exemplo, na coluna 1 - linha A foram acrescentados 
$50 \mu \mathrm{L}$ da microcápsula CAP 0 de concentração conhecida. Em seguida, $100 \mu \mathrm{L}$ do conteúdo do orifício foram homogeneizados com o meio e transferidos para o orifício da linha seguinte (linha B), repetindo-se esse procedimento até a linha $\mathrm{H}$ de modo a se obter concentração decrescente do material. Os $100 \mu \mathrm{L}$ finais foram desprezados. Em seguida, $100 \mu \mathrm{L}$ de suspensão do microorganismo de crescimento recente (24 horas), cuja turvação foi comparada à escala de McFarland $\mathrm{n}^{0} 0,5$ e diluídos para concentração final de $10^{4}$ células. $\mathrm{mL}^{-1}$ foram adicionados. As placas foram seladas com parafilme e incubadas por $24 \mathrm{~h}$ a $37^{\circ} \mathrm{C}$. Após esse período foi acrescentado $20 \mu \mathrm{L}$ de solução aquosa de TTC (cloreto de trifenil tetrazolium) a 0,5\%, sendo a placa reincubada por $3 \mathrm{~h}$ na referida temperatura. A concentração inibitória mínima (MIC) foi definida como a menor concentração da amostra capaz de impedir o aparecimento de coloração vermelha.

\subsection{ANÁLISE ESTATÍSTICA}

Para a avaliação estatística dos resultados utilizou-se Delineamento Inteiramente Casualizado (DIC), sendo efetuadas análises de variância com posterior comparação entre as médias pelo teste de Tukey ao nível de $5 \%$ de probabilidade. As análises foram realizadas utilizandose o programa ASSISTAT versão 6.7 beta (SILVA e AZEVEDO, 2002).

\section{RESULTADOS E DISCUSSÃO}

A Tabela 3 mostra os parâmetros de cor para a dextrina, o amido OSA e a bLF utilizados como matérias-prima para a obtenção das microcápsulas. A bLF apresentou menor luminosidade que a dextrina e o amido OSA, além de altos valores dos parâmetros $a^{*}$ e $b^{*}$, indicando a coloração vermelho-amarelada (alaranjada) da proteína. A dextrina revelou cor mais amarelada ( $\left.b^{\star}\right)$ que o amido OSA, material mais claro devido sua maior luminosidade.

TABELA 3 - VALORES DA LUMINOSIDADE (L*) E DAS COORDENADAS DE CROMATICIDADE $\left(a^{*} E b^{*}\right)$ PARA DEXTRINA, AMIDO OSA E BLF

\begin{tabular}{cccc}
\hline Material & $\mathbf{L}^{*}$ & $\mathbf{a}^{*}$ & $\mathbf{b}^{*}$ \\
\hline Dextrina & $92,72 \mathrm{~b}$ & $0,04 \mathrm{~b}$ & $12,96 \mathrm{~b}$ \\
Amido OSA & $94,17^{\mathrm{a}}$ & $0,03 \mathrm{~b}$ & $9,750 \mathrm{c}$ \\
bLF & $59,01 \mathrm{c}$ & $17,44 \mathrm{a}$ & $15,42 \mathrm{a}$ \\
\hline
\end{tabular}

a,b,c Médias na mesma coluna com letras diferentes diferem entre si significativamente pelo teste de Tukey a 5 \% de probabilidade. Médias de duplicatas.

Todas as microcápsulas produzidas apresentaram coloração creme, representada pelos valores $L^{*}$ entre 92,15 e 93,01; $a^{*}$ entre 2,18 e 2,47 e $b^{*}$ entre 7,78 e 9,05.

Conforme a Tabela 4, as microcápsulas CAP 50 evidenciaram a maior luminosidade entre as amostras e as microcápsulas CAP 0 e CAP 100 (que não diferiram significativamente entre si) a menor luminosidade.

As microcápsulas CAP 0 apresentaram os maiores valores para os parâmetros $\mathrm{a}^{\star}($ vermelho) e b* (amarelo) e as microcápsulas CAP 50 o menor valor para a intensidade de vermelho ( $a^{*}$ ). Já as microcápsulas CAP 25, 75 e 100, estatisticamente iguais, mostraram intensidades de vermelho intermediárias (Tabela 4).

Para a intensidade do amarelo $\left(b^{\star}\right)$, as microcápsulas CAP 25 apresentaram valor intermediário e as CAP 50, 75 e 100 os menores valores (Tabela 4). 


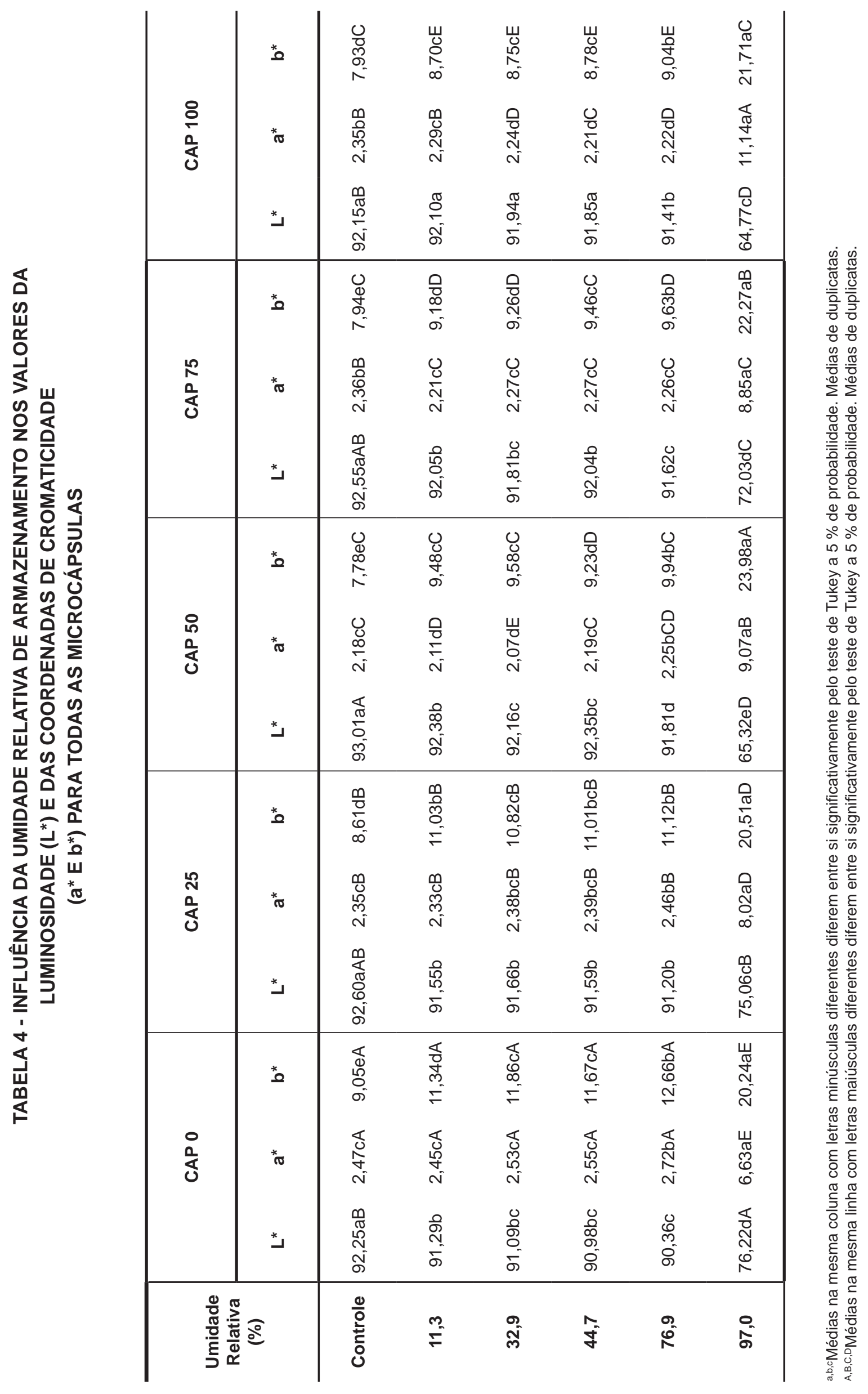


O valor $L^{*}$ constitui medida da fração claro-escuro da cor superficial do alimento (MASKAN, 2001). Analisando a Tabela 4 verifica-se que as microcápsulas produzidas apresentaram cor clara, caracterizada pela alta luminosidade. Esse resultado indica que a dextrina e/ou amido OSA foram os componentes que mais contribuíram para a luminosidade das microcápsulas, devido possivelmente a maior proporção desses em relação a bLF (núcleo).

Os valores de $L^{*}$ obtidos para as microcápsulas produzidas também indicam ausência de escurecimento não enzimático durante a produção das microcápsulas por spray drying. Ibarz, Pagan e Garza (1999) propuseram que a variação da luminosidade de amostras secas pode ser considerada como medida do escurecimento não enzimático ocorrido.

Verifica-se pela avaliação dos valores de $\mathrm{a}^{\star} \mathrm{e}^{\star}$ (Tabela 4), que o parâmetro de cromaticidade mais acentuado nas microcápsulas foi o amarelo.

As soluções contendo os diferentes materiais de parede e o núcleo, que deram origem as microcápsulas CAP 0, CAP 25, CAP 50, CAP 75 e CAP 100 evidenciaram coloração alaranjada, embora a dextrina e/ou amido OSA representassem a fração predominante da solução (material de parede: núcleo, 4:1). Após o processo de atomização das soluções para obtenção das respectivas microcápsulas ocorreu inversão da cor predominante, de avermelhada (solução) para amarelada (pó). Tal resultado sugere que a superfície externa das microcápsulas formadas foi constituída principalmente pela dextrina e/ou amido OSA e, consequentemente, a bLF está na parte mais interna das microcápsulas.

$\mathrm{Na}$ Tabela 4 verifica-se a influência da umidade relativa de armazenamento nos valores de luminosidade $\left(L^{*}\right)$ e nas coordenadas de cromaticidade $\left(a^{*}\right.$ e $\left.b^{\star}\right)$ para as diferentes microcápsulas produzidas. O aumento da umidade relativa de armazenamento afetou diferentemente a luminosidade das microcápsulas, provocando escurecimento das CAP 0 em relação à amostra controle. Verificou-se, respectivamente, o maior e o menor escurecimento das amostras em umidade relativa de $97 \%$ e $11,3 \%$. Não houve diferença significativa nos valores de luminosidade da microcápsula CAP 0 em umidade relativa de $32,9 \%$ e 44,7\% e esses valores foram estatisticamente iguais aos obtidos em umidade relativa de $11,3 \%$ e $76,9 \%$.

O armazenamento das microcápsulas CAP 25 (Tabela 4) em umidades relativas de $11,3 \%$ a $76,9 \%$ diminuiu sua luminosidade em relação ao controle, mas não foi constatada diferença significativa entre esses valores. Em umidade relativa de armazenamento de $97 \%$ houve significativa diminuição da luminosidade da amostra.

$O$ aumento da umidade relativa de armazenamento provocou escurecimento significativo das microcápsulas CAP 50, exceto para a umidade relativa de 44,7 \% (Tabela 4).

Umidades relativas de armazenamento de $11,3 \%$ a $44,7 \%$ afetaram igualmente a luminosidade das microcápsulas CAP 75 , provocando diminuição desses valores em relação ao controle. A maior redução da luminosidade das microcápsulas CAP 75 ocorreu em umidade relativa de $97 \%$.

O armazenamento das CAP 100 (Tabela 4) em umidades relativas de 11,3\% até 44,7 \% não provocou o escurecimento das microcápsulas, o qual só ocorreu durante armazenamento em umidades relativas altas (76,9\% e $97 \%)$.

Acredita-se que o escurecimento verificado nas microcápsulas estudadas durante o armazenamento em ambientes com umidade relativa menor ou igual a 76,9 \% seja causado pela interação da dextrina e/ou amido OSA com a água. Conforme verificado por Maia et al. (2004), a dextrina apresenta maior capacidade de absorção de água que o amido OSA. Essa teoria explicaria a diminuição da luminosidade das microcápsulas contendo dextrina e sua manutenção nas microcápsulas contendo somente o amido OSA como material de parede (CAP 100).

O escurecimento verificado durante o armazenamento em umidade relativa de $97 \%$ sugere que a alta umidade do ambiente promoveu a desintegração das microcápsulas, 
mediante dissolução do material da parede, resultando na exposição da bLF.

Quanto ao parâmetro de cromaticidade a* (intensidade de vermelho) não houve diferença significativa entre as microcápsulas CAP 0 , controle e as armazenadas em umidade relativa de $11,3 \%$ a 44,7 \%. Contudo, verificou-se significativa acentuação da cor vermelha em umidades relativas de armazenamento maiores que $44,7 \%$. Resultados similares foram observados para as microcápsulas CAP 25 (Tabela 4).

As microcápsulas CAP 50 (Tabela 4) armazenadas em umidade relativa de 44,7\% não apresentaram variação no parâmetro $a^{*}$ em relação ao controle. Não houve diferença significativa entre os valores de $\mathrm{a}^{*}$ obtidos em umidades relativas de armazenamento de $11,3 \%$ e 32,9 \%, embora tenha ocorrido diminuição da cor vermelha das microcápsulas quando comparadas ao controle. Para as demais umidades relativas de armazenamento, os valores de $a^{*}$ aumentaram com a elevação da umidade.

Umidades relativas de armazenamento de 11,3 \% a 76,9 \% afetaram igualmente o parâmetro a* das microcápsulas CAP 75, provocando diminuição da sua cor vermelha. As microcápsulas armazenadas em umidade relativa de $97 \%$ apresentaram aumento da coloração vermelha (Tabela 4).

Microcápsulas CAP 100 (Tabela 4) armazenadas em umidades relativas de 11,3 \% e 76,9 \% apresentaram diminuição do parâmetro a* em relação ao controle, sendo os menores valores obtidos em umidades relativas de 32,9 \%, 44,7 \% e 76,9 \% (estatisticamente iguais). Em umidade relativa de $97 \%$ ocorreu acentuação da cor vermelha das microcápsulas, assim como verificado para as demais.

Para os valores do parâmetro $b^{*}$ (intensidade de amarelo) houve intensificação da cor amarela para todas as microcápsulas (CAP 0 a CAP 100) durante o armazenamento em todas as umidades relativas estudadas (Tabela 4).

Constatou-se incremento dos valores de $b^{*}$ das microcápsulas CAP 0 conforme elevação da umidade relativa de armazenamento, exceto para as umidades relativas de $32,9 \%$ e 44, 7 \% que não mostraram diferença significativa entre si.

As microcápsulas CAP 25 (Tabela 4) apresentaram a mesma intensidade de amarelo quando armazenadas em umidades relativas de $11,3 \%$ e $76,9 \%$, maior que a verificada com armazenamento em umidade relativa de $32,9 \%$. Contudo, a coloração amarela mais intensa foi obtida sob armazenamento em umidade relativa de $97 \%$.

Os valores de $b^{*}$ das microcápsulas CAP 50 (Tabela 4) em umidade relativa de armazenamento de $11,3 \%$ e de $32,9 \%$ não apresentaram diferença significativa entre si e foram maiores que os verificados para o armazenamento em umidade relativa de $44,7 \%$. O armazenamento em umidades relativas de $97 \%$ e de $76,9 \%$ resultou na obtenção dos maiores valores de b*, respectivamente.

Com exceção das microcápsulas armazenadas em umidades relativas de 11,3 \% e 32,9 \%, que não mostraram diferença significativa entre si, as microcápsulas CAP 75 (Tabela 4) apresentaram intensificação da coloração amarela conforme o aumento da umidade relativa de armazenamento.

O armazenamento em umidades relativas de $11,3 \%$ a $44,7 \%$ afetou igualmente 0 parâmetro b* das microcápsulas CAP 100, provocando elevação desses valores significativamente menor que os aumentos obtidos em umidades relativas de armazenamento de $76,9 \%$ e $97 \%$, respectivamente.

Ramírez-Jiménez, Guerra-Hernández e García-Villanova (2003) verificaram que o armazenamento de cereal matinal de arroz em atividade de água de 0,65 a $25^{\circ} \mathrm{C}$ por 4 semanas favoreceu a ocorrência de escurecimento não enzimático no alimento, que pode ser monitorado pela avaliação do parâmetro b* da análise de cor.

No presente estudo, constatou-se aumento drástico do valor do parâmetro $b^{\star}$ para todas as microcápsulas estudadas (CAP 0 a CAP 100) acondicionadas em umidade relativa de $97 \%$, sugerindo a ocorrência de escurecimento não enzimático durante o armazenamento. Em ambientes 
com baixa umidade relativa, a mobilidade inadequada representa o fator limitante para a ocorrência do escurecimento enzimático (KAREL, 1975).

Os valores de luminosidade mostraram-se similares para todas as microcápsulas armazenadas em umidades relativas de $11,3 \%$ a 76,9 \%. Contudo, em umidade relativa de $97 \%$, as microcápsulas CAP 0 e CAP 25 apresentaram os maiores valores de luminosidade. As microcápsulas CAP 50 e CAP 100 não revelaram diferença significativa entre si e evidenciaram os menores valores de luminosidade.

Em umidade relativa de armazenamento de $11,3 \%$, a maior intensidade da cor vermelha foi verificada nas microcápsulas CAP 0 e a menor nas microcápsulas CAP 50.

Quando o armazenamento ocorreu em umidade relativa de 32,9\%, as microcápsulas que apresentaram maior intensidade de vermelho foram CAP 0, CAP 25, CAP 75 e CAP 100, respectivamente. As microcápsulas CAP 50 mostraram coloração vermelha menos intensa.

As microcápsulas CAP 50, CAP 75 e CAP 100 não apresentaram diferença significativa para os valores de $a^{*}$ sob armazenamento em umidade relativa de 44,7 \% (Tabela 4), revelando a menor intensidade de vermelho. Os maiores valores de $a^{\star}$ foram verificados nas microcápsulas CAP 0 e CAP 25.

Em umidade relativa de 76,9 \% (Tabela 4), com exceção das microcápsulas CAP 50, a intensidade da cor vermelha das microcápsulas diminuiu com o aumento da proporção de amido OSA.

A intensidade da cor vermelha em umidade relativa de armazenamento de $97 \%$ foi maior para as microcápsulas CAP 100, CAP 50 e CAP 75, respectivamente. Já os menores valores para a cor vermelha foram verificados nas microcápsulas CAP 0 e CAP 25.

Para o parâmetro b* (Tabela 4), quanto maior a proporção de amido OSA nas microcápsulas sob armazenamento em umidades relativas de $11,3 \%, 32,9 \%$ e 76,9 \% menor foi a intensidade do amarelo. As amostras mais amarelas foram as microcápsulas CAP 0 e as menos amarelas as microcápsulas CAP 100. Resultados similares foram verificados em umidade relativa de armazenamento de 44,7 \% (Tabela 4), com exceção das microcápsulas CAP 50 que apresentaram coloração menos amarela que as CAP 75.

Sob armazenamento em umidade relativa de $97 \%$, as microcápsulas que apresentaram coloração amarela mais acentuada foram CAP 50, CAP 75 e CAP 100, respectivamente.

As MIC da bLF e das microcápsulas CAP 0 a CAP 100 para diferentes bactérias Gram positivas, Gram negativas e levedura estão apresentadas nas Tabelas 5 e 6 , respectivamente.

Analisando a Tabela 5 verifica-se que as microcápsulas estudadas apresentaram atividade contra as bactérias, embora a MIC tenha variado conforme o tipo de micro-organismo testado. Para as bactérias B. subtilis, S. aureus e M. luteus, a menor MIC (50 mg. $\left.\mathrm{mL}^{-1}\right)$ foi constatada para as microcápsulas CAP 50. Já para o E. faecium, a menor MIC verificada foi de $60 \mathrm{mg} \cdot \mathrm{mL}^{-1}$ para as microcápsulas CAP 25.

Com relação ao S. faecium, as microcápsulas CAP 0, CAP 25, CAP 50 e CAP 75 evidenciaram a mesma MIC, entre $40-80 \mathrm{mg} \cdot \mathrm{mL}^{-1}$. Todas as microcápsulas apresentaram MIC maior que $80 \mathrm{mg} \cdot \mathrm{mL}^{-1}$ para $R$. equi.

Conforme a Tabela 6, as microcápsulas CAP 25 apresentaram a menor MIC (50 mg.mL) para $P$. aeruginosa. Para S. choleraesius, a menor MIC foi verificada para as microcápsulas CAP $100\left(60 \mathrm{mg} \cdot \mathrm{mL}^{-1}\right)$. Todas as microcápsulas exibiram MIC maior que $80 \mathrm{mg}^{\mathrm{mL}} \mathrm{mL}^{-1}$ para E. coli.

Os resultados obtidos para $C$. albicans indicaram alta atividade antifúngica das microcápsulas CAP 75, com MIC igual a 2,5 mg. $\mathrm{mL}^{-1}$.

Analisando-se as Tabelas 5 e 6 verifica-se que, com exceção do $B$. subtilis, a concentração de bLF contida nas microcápsulas necessária para inibir o crescimento dos demais micro-organismos foi menor do que a da bLF nativa.

Segundo Farnaud e Evans (2003), a combinação de bLF com fluconazol reduziu a MIC necessária para inibição de espécies de Candida sp., indicando o seu uso potencial em terapias 
contra infecções em pacientes contaminados com o vírus HIV que apresentam frequentemente infecções causadas por espécies de Candida sp. resistentes ao fluconazol.

\section{TABELA 5 - DETERMINAÇÃO DA CONCENTRAÇÃO INIBITÓRIA MÍNIMA (MIC) DA LACTOFERRINA BOVINA (bLF) E DAS MICROCÁPSULAS \\ CONTENDO bLF (CAP O A CAP 100) PARA BACTÉRIAS GRAM POSITIVAS}

\begin{tabular}{cccccccc}
\hline \multirow{2}{*}{$\begin{array}{c}\text { Bactérias } \\
\text { Gram positivas }\end{array}$} & CAP 0 & CAP 25 & CAP 50 & CAP 75 & CAP 100 & bLF & PADRÃO* \\
\cline { 2 - 8 } & & & & & & \\
Cacillus subtilis & 100 & 90 & 50 & 50 & 50 & 5 & 0,004 \\
Staphylococcus aureus & $>80$ & $>80$ & 50 & 65 & 60 & 40 & $<0,002$ \\
Micrococcus luteus & $>80$ & 90 & 50 & 50 & $>80$ & $>80$ & 0,008 \\
Enterococcus faecium & $>80$ & 60 & $>80$ & $>80$ & $>80$ & 50 & 0,008 \\
Streptococcus faecium & $40-80$ & $40-80$ & $40-80$ & $40-80$ & $>80$ & $>80$ & 0,004 \\
Rhodococcus equi & $>80$ & $>80$ & $>80$ & $>80$ & $>80$ & $>80$ & 0,004 \\
\hline
\end{tabular}

* Padrão para bactérias Gram positivas = cloranfenicol.

Segundo Brock (2002), o mecanismo que tem sido proposto para a atividade antimicrobiana da bLF baseia-se na sua capacidade de romper ou penetrar a membrana celular da bactéria.

Recio e Visser (2000) verificaram que o domínio catiônico denominado de lactoferricina, liberado por hidrólise péptica da região N-terminal da bLF, apresenta atividade antimicrobiana maior que a proteína intacta. As principais características determinantes da atividade de perturbação da membrana causada por esses peptídeos envolvem seu caráter anfifílico, conformação de $\alpha$-hélice e carga líquida positiva.

\section{TABELA 6 - DETERMINAÇÃO DA CONCENTRAÇÃO INIBITÓRIA MÍNIMA (MIC) DA LACTOFERRINA BOVINA (bLF) E DAS MICROCÁPSULAS CONTENDO bLF (CAP O A CAP 100) PARA BACTÉRIAS GRAM NEGATIVAS E LEVEDURA}

\begin{tabular}{|c|c|c|c|c|c|c|c|}
\hline \multirow{2}{*}{ Bactérias Gram Negativas } & \multicolumn{7}{|c|}{ MIC (mg.mL-1) } \\
\hline & $\begin{array}{c}\text { CAP } \\
0\end{array}$ & $\begin{array}{c}\text { CAP } \\
25\end{array}$ & $\begin{array}{c}\text { CAP } \\
50\end{array}$ & $\begin{array}{c}\text { CAP } \\
75\end{array}$ & $\begin{array}{l}\text { CAP } \\
100\end{array}$ & bLF & PADRÃO* \\
\hline Pseudomonas aeruginosa & $>80$ & 50 & $>80$ & $>80$ & $>80$ & $>80$ & $>0,25$ \\
\hline Samonella choleraesius & 100 & 90 & $>80$ & 65 & 60 & $>80$ & 0,008 \\
\hline Escherichia coli & $>80$ & $>80$ & $>80$ & $>80$ & $>80$ & $>80$ & 0,004 \\
\hline \multicolumn{8}{|l|}{ Levedura } \\
\hline Candida albicans & $>80$ & $>80$ & $>80$ & 2,5 & 40 & $>80$ & $<0,002$ \\
\hline
\end{tabular}

* Padrão para bactérias Gram negativas = cloranfenicol; Padrão para leveduras = nistatina.

De acordo com Schibli et al. (2002), vários peptídeos e proteínas com atividade 
antimicrobiana são ricos em triptofano. Esse aminoácido apresenta a capacidade de se inserir nas membranas dos micro-organismos, causando seu rompimento.

Os resultados obtidos sugerem efeito de potencialização da atividade antimicrobiana da bLF após o processamento por spray drying, embora não seja possível elucidar os mecanismos de ação envolvidos por meio do presente estudo.

\section{CONCLUSÁO}

Nas condições experimentais utilizadas neste trabalho e de acordo com os resultados obtidos, as microcápsulas produzidas apresentaram cor clara e tenderam a escurecer sob armazenamento em ambientes com alta umidade relativa, indicando que o processo de microencapsulação utilizado foi eficiente para proteger e modificar a cor original da lactoferrina bovina. Além disso, verificou-se que o processo de microencapsulação resultou na potencialização da atividade antimicrobiana da bLF. Desta forma, a microencapsulação da bLF representa alternativa viável para sua utilização como agente antimicrobiano nos mais diferentes sistemas alimentares.

\section{ABSTRACT \\ COLOR AND ANTIMICROBIAL ACTIVITY ANALYSIS OF MICROCAPSULES CONTAINING BOVINE LACTOFERRIN}

Bovine Lactoferrin (bLF) derived from whey was microencapsulated by spray drying. Microcapsules with $20 \%$ of bLF were produced using, dextrin:octenylsuccinate starch (OSA) as wall materials at varied ratios of 100:00, $75: 25,50: 50,25: 75$ and 0:100 \%. The color, and stability of color, under storage in different relative humidities, as well as the antimicrobial activity of the microcapsules, were all analyzed. The microcapsules were clear in color and tended to darken in storage in environments with high relative humidity. Inhibiting activity by the microcapsules of bLF was found, which was produced by different Gram-positive bacteria (Bacillus subtilis CCT 2576, Staphylococcus aureus CCT 2740, Micrococcus luteus CCT 2692, Enterococcus faecium CCT 5079, Streptococcus faecium ATCC 10541, Rhodococcus equi CCT 0541); Gram-negative bacteria (Pseudomonas aeruginosa ATCC 13388, Salmonella choleraesius CCT 4296, Escherichia coli CCT 0547) and yeast (Candida albicans ATCC 10231). The minimum inhibitory concentration (MIC) of the microcapsules varied according to the tested microorganisms (MICs between 2.5-100 mg.mL-1). With the exception of B. subtilis (MIC between 50$100 \mathrm{mg} \cdot \mathrm{mL}-{ }^{-1}$ ), the concentration of bLF contained in the microcapsules that was necessary to inhibit the growth of microorganisms was lower than the native bLF. These results suggest a potential effect of bLF antimicrobial activity after processing by spray drying.

KEY-WORDS: MICROENCAPSULATION; SPRAY DRYING; LACTOFERRIN.

\section{REFERÊNCIAS}

1 AGUILA LA O, A.; BROCK,J.H. Lactoferrin: antimicrobial and diagnostic properties. Biotecnologia aplicada, v. 18,n.2, p.76-83, 2001.

2 AL-NABULSI, A.A.; HOLLEY, R.A. Effects on Escherichia coli O157:H7 and meat starter cultures of bovine lactoferrin in broth and microencapsulated lactoferrin in dry sausage batters. International Journal of Food Microbiology, v.113, p.84-91, 2007.

3 APPELMELK, B.J.; AN, Y.K.; GEERTS, M.; THIJS, B.G.; DE BOER, H.A.; MACLAREN, D M.; DE GRAAFF, J.; NUIJENS, J.H. Lactoferrin is a lipid a-binding protein. Infection and Immunity, v.62, p.2628-2632, 1994.

4 AVILA, I.M.L.; SILVA, C.L.M. Modelling kinetics of thermal degradation of colour in peach puree. Journal of Food Engineering, v.39, p.161-166, 1999.

5 BROCK, J.H. The physiology of lactoferrin. Biochemistry and Cell Biology, v.80, p.1-6, 2002.

6 DELLA MODESTA, R.C. Manual de análise sensorial de alimentos e bebidas: geral. Rio de Janeiro: EMBRAPACTAA, 1994.

7 ELOFF, J.N. A sensitive and quick microplate method to determine the minimal inhibitory concentration of plant extracts for bactéria. Planta Médica V, v.64, n.8, p.711-713, 1998.

8 FARNAUD, S.; EVANS, R.W. Lactoferrin - a multifunctional protein with antimicrobial properties. Molecular Immunology, v.40, p.395-405, 2003 
9 GREENSPAN, L. Humidity fixed points of binary saturated aqueous solutions. Journal of Research of the National Bureau of Standards, v.81A, p.89-112, 1977.

10 HOGAN, S.A.; MCNAMEE, B.F.; O'RIORDAN, E.D.; O'SULLIVAN, M. Emulsification and microencapsulation properties of sodium caseinate/ carbohydrate blends. International Dairy Journal, v.11, p.137-144, 2001.

11 HUTCHINGS, J.B. Food colour and appearance. London: Chapman and Hall, 1994.

12 IBARZ, A.; PAGAN, J.; GARZA, S. Kinetics models for colour changes in pear puree during heating at relatively high temperatures. Journal of Food Engineering, v.39, p.415-422, 1999.

13 KAREL, M. Water activity and food preservation. In: KAREL, M.; FENNEMA, O.R.; LUND, D.B. Principles of food science. Part II: physical principles of food preservation. New York: Marcel Dekker, 1975. p. 237-264.

14 LABUZA, T.P. Sorption phenomena in foods. Food Technology, v.22, n.3, p.263-272, 1968.

15 MAIA, L.H.; CORNEJO, F.E.P.; ASCHERI, D.P.R.; MAIA, M.C.A.; ROCHA-LEÃO, M.H.M. Moisture sorption studies on lactoferrin microcapsules. Alimentaria, v.356, p.79-87, 2004.

16 MAIA PORTE, L.H.; ROCHA LEÃO, M.H.M. ; PORTE, A. Avaliação da porosidade de microcápsulas contendo proteína bioativa por porosimetria de mercúrio e adsorção de nitrogênio. Química Nova, v.34, n.9, p.1582-1587, 2011.

17 MASKAN, M. Kinetics of colour change of kiwi fruits during hot air and microwave drying. Journal of Food Engineering, v.48, p.169-175, 2001.

18 MURDOCK, C.A.; MATTHEWS, K.R. Antibacterial activity of pepsin-digested lactoferrin on foodborne pathogens in buffered peptone broth systems and ultra-high temperature milk with EDTA. Journal of Applied Microbiology, v.93, p. 850-856, 2002.

19 PITALUA, E.; JIMENEZ, M.; VERNON-CARTER, E.J.; BERISTAIN, C.I. Antioxidative activity of microcapsules» with beetroot juice using gum Arabic as wall material. Food and Bioproducts Processing, v.88, n.2-3, p.253-258, 2010.

20 RAMÍREZ-JIMÉNEZ, A.; GUERRA-HERNÁNDEZ, E.; GARCÍA-VILLANOVA, B. Evolution of non-enzymatic browning during storage of infant rice cereal. Food Chemistry, v.83, p.219-225, 2003.

21 RECIO, I.; VISSER, S. Antibacterial and binding characteristics of bovine, ovine and caprine lactoferrins: a comparative study. International Dairy Journal, v.10, p.597-605, 2000.

22 ROCHA, G.A.; FÁVARO-TRINDADE, C.S.; GROSSO, C.R.F. Microencapsulation of lycopene by spray drying: characterization, stability and application of microcapsules. Food and Bioproducts Processing, v.90, n.1, p.37-42, 2012.

23 SCHILIBI, D.J.; EPAND, R.F.; VOGEL, H.J.; EPAND, R.M. Tryptophan-rich antimicrobial peptides: comparative properties and membrane interactions. Biochemistry and Cell Biology, v.80, p.667-677, 2002. SHIMAZAKI, K. Lactoferrin: a marvellous protein in milk. Animal Science Journal, v.71, p.329-347, 2000.

25 SILVA, F.A. S.E.; AZEVEDO, C.A.V. Versão do programa computacional Assistat para o sistema operacional Windows. Revista Brasileira de Produtos Agroindustriais, v.4, n.1, p.71-78, 2002.

26 WONG, M.; STANTON, D.W. Effect of removal of amino acids and phenolic compounds on non-enzymatic browning in stored kiwi fruit juice concentrates. Lebensmittel Wissenchaft und Technologie, v.26, p.138-143, 1992. 